\title{
Investigating the Interaction Effect of Democracy and Economic Freedom on Corruption: A Cross-Country Quantile Regression Analysis
}

\author{
Shrabani Saha ${ }^{1}$ \\ School of Accounting Finance and Economics, \\ Edith Cowan University, \\ 270 Joondalup Drive, Joondalup, WA-6027, \\ Australia \\ (Email: s.saha@ecu.edu.au) \\ and \\ Jen-Je Su \\ Department of Accounting, Finance and Economics, \\ Griffith University, \\ Nathan QLD 4111, \\ Australia \\ (Email:j.su@griffith.edu.au)
}

Abstract: $\quad$ This paper explores the interaction effects of economic freedom and democracy in controlling corruption for 100 countries by using quantile regression technique. The main contribution is to explore the interaction effects throughout conditional distribution of corruption across nations. Our results reinforce some findings in the literature, but also provide new conclusions. The findings suggest a stronger and significant interaction effect in reducing corruption, especially in the most-corrupt countries. However, democratic and economic freedoms alone may not cure corruption effectively in the most-corrupt nations, a sound democratic reform can eliminate corruption substantially only after achieving a threshold level of economic freedom.

\section{INTRODUCTION}

Most cross-country empirical research on the consequences of corruption affirms its detrimental effect on growth and development. Given this negative impact, much stands to be gained from understanding the causes of and ways of reducing corruption. Economists and policy makers have emphasized the role of institutional factors such as economic and political freedom in combating corruption (Treisman 2007, Graeff and Mehlkop 2003, Bliss and Di Tella 1997,

1 Corresponding Author: s.saha@ecu.edu.au. 
Rose-Ackerman 1978, and Krueger 1974). Some consensus is slowly emerging in the literature, although several aspects remain unresolved. For instance, even though most studies confirm that greater economic freedom reduces corruption, the role of democracy remains unclear (Rock 2007, Montinola and Jackman 2004, Mohtadi and Roe 2003, Treisman 2000, and Ades and Di Tella 1999). Furthermore, the current literature is lacking behind to answer, whether more economic freedom and greater democracy consistently reduce corruption among the most and the least corrupt nations. We address this issue as corruption control is a crucial concern from a policy perspective especially for the developing countries.

This paper analyzes the joint effects of democracy and economic freedom in combating corruption by utilizing quantile regression technique. Quantile regression technique has its advantages over ordinary least squares (OLS), instrumental variables, and panel estimation as it estimates the interaction effect on corruption throughout the conditional distribution of corruption. $^{2}$

Saha, Gounder and Su (2009) (hereafter, SGS) assessed the interactive effect of democracy and economic freedom in controlling corruption, and the findings reflect that democracy and economic freedom were complementing in reducing corruption. Specifically, while economic freedom reduces corruption in any political environment, it is more effective with a higher level of democracy. However, democracy can increase corruption if economic freedom is low and will reduce corruption only above a certain threshold of economic freedom. Billiger and Goel (2009) in contrast, found that among the most-corrupt nations, greater economic freedom does not appear to reduce corruption, but greater democracy does. However, unlike SGS (2009), Billiger and Goel (2009) did not consider the interaction effect.

This paper investigates SGS (2009) by utilizing quantile regression. In particular this paper focuses on the distribution of the corruption perception index to identify whether the interaction effects of democracy and economic freedom vary over different quantiles - i.e., does the interaction effect differ in highly-corrupt nations compared to the least-corrupt ones? There may be extensive institutional differences between clean and corrupt countries that may influence the efficacy of combating corruption even when the same level of democracy and economic freedom exists in the most-corrupt and clean countries. ${ }^{3}$ In that case the findings have significant policy implication for the most corrupt and the least corrupt countries i.e., the policy recommendations to cure corruption could be varied in nature depending on the particular characteristics of the most corrupt and the least corrupt countries.

The interaction effect results support some findings in the literature, but also contributed to the literature by adding the results of the sensitivity of the distribution of the dependent variable corruption. Quantile regression results mainly differ in terms of the most and least corrupt nations suggesting that some of the policy implications regarding anti-corruption reform based on ordinary least squares analysis require to be reconsidered. The next section discusses the model, data and estimation methodology followed by results and conclusion.

2 OLS, instrumental variables and panel regressions estimate the parameters of interest at the mean evaluation by a conditional distribution of the dependent variable (Billger and Goel 2009 and Okada and Samreth 2012).

3 Goel and Nelson (2007) show the contagion effects of corruption for the United States. 


\section{THE MODEL, DATA AND ESTIMATION METHODOLOGY}

Following SGS (2009), the model is specified as:

$$
\begin{aligned}
& C P I_{i}=\beta_{0}+\beta_{1} D E M O_{i}+\beta_{2} E F_{i}+\beta_{3} D E M O_{i} * E F_{i}+\beta_{4} \log (R G D P)_{i}+\beta_{5} G I N I_{i} \\
& +\beta_{6} \text { UNEM }_{i}+\beta_{7} A L R_{i}+\varepsilon_{i}
\end{aligned}
$$

where CPI is corruption perception index, the last four terms are socio-economic control variables i.e., real gross domestic product per capita (RGDP), Gini index for income inequality (GINI), unemployment rate (UNEM) and adult literacy rate (ALR) and $\varepsilon$ is the error term and i denotes country.

In estimating Equation (1), we are particularly concerned with the coefficient $\beta 3$, which captures the interaction effect. The coefficients of RGDP, GINI, UNEM and ALR in Equation (1) are of less interest although they help to establish the plausibility of the overall results. We expect that perceived corruption will fall, the higher the per capita income and literacy rate and the lower the unemployment and income inequality.

Corruption defined as misuse of public offices is a perception based subjective index. Transparency International's annual corruption perception index (CPI) is used as the measure of corruption (the dependent variable). ${ }^{4}$ The democracy index (DEMO) is constructed by combining Freedom House political rights, civil liberties and press freedom indices. ${ }^{5}$ The economic freedom index (EF) is a composite index obtained from the Heritage Foundation. ${ }^{6}$ We re-scale CPI, DEMO and EF from 0 to 10, with a low value of CPI representing a low level of corruption and low DEMO and EF indicating lower freedoms. The data for this study includes cross-sectional observations for 100 countries with all variables averaged over the period 1995-2008. ${ }^{7}$

Equation (1) is estimated by using OLS and the regression quantile estimation. Unlike the standard OLS estimation which yields a result at the conditional mean of the dependent variable (corruption), the quantile regression estimates results throughout the conditional distribution of corruption. This allows comparison of how different percentiles of the corruption level i.e., the least-and-most-corrupt (the low and high-quantile, respectively) countries are affected by democracy, economic freedom and their interaction. Quantile regression, developed in Koenker and Bassett (1978), estimates the regression parameters at different points in the conditional distribution of the dependent variable. Specifically, the $\theta^{\text {th }}$ regression quantile solves the following minimization problem:

$$
\min _{\beta \in R^{k}}\left[\sum_{t \in\left\{t: y_{,}, x_{i}, \beta\right\}} \theta\left|y_{t}-X_{t}^{\prime} \beta\right|+\sum_{t \in\left\{t: y_{t}<x_{t} \beta\right\}}(1-\theta)\left|y_{t}-X_{t}^{\prime} \beta\right|\right]
$$

where $0<\theta<1$. In Equation (2), $y_{t}$ is the corruption index (CPI) and the vector $X_{t}$ contains

4 For details see http://www.transparency.org/policy_research/surveys_indices/cpi.

5 See http://www.freedomhouse.org for details.

6 Economic freedom index is an arithmetic mean of eight individual freedoms (i.e., business freedom, trade freedom, monetary freedom, freedom from government, fiscal freedom, property right, investment freedom and financial freedom). See http://www.heritage.org for details.

7 The data sources are same as those in SGS (2009). 
the independent variables shown in equation (1). The conditional quantile of $y_{t}$ given $X_{t}$ is $Q_{y}\left(\theta \mid x_{t}\right)=x_{t} \beta_{\theta}$ where $\beta_{\theta}$ is the slope at the $\theta$ th quantile.

We hypothesise that democracy and economic freedom should have a complementary effect in bringing down corruption and consequently the interaction effect $\left(\beta_{3}\right)$ is negative. The partial effects of democracy and economic freedom on corruption are computed to identify the individual impact of democracy (economic freedom) for a given level of economic freedom (democracy) for different quantiles. Specifically, the partial effects of democracy and economic freedom on corruption at quantile $(\theta)$ are computed as follows:

$$
\begin{aligned}
& \triangle C P I_{i} / \triangle D E M O_{i}(\text { givenEFand } \theta)=\beta_{1 \theta}+\beta_{3 \theta} * E F_{i} \\
& \Delta C P I_{i} / \triangle E F_{i}(\text { givenDEMOand } \theta)=\beta_{2 \theta}+\beta_{3 \theta} * D E M O_{i}
\end{aligned}
$$

\section{EMPIRICAL RESULTS}

The results of the base model (1) for OLS and regression quantiles (given $\theta=0.1,0.3,0.5$, $0.7,0.9)$ are presented in Table 1 . OLS estimates provide a baseline of mean effects, and we compare these to estimate for separate quantiles in the conditional distribution of corruption. ${ }^{8}$ The following observations are noted. First, the OLS result (at the conditional mean) and the quantile result at $\theta=0.5$ (at the conditional median) are similar across different parameters. Second, among the five quantiles, there is considerable variability for each parameter (for example, at $\theta=0.1$, the coefficients for DEMO and EF are 0.16 and -0.66 , respectively; while at $\theta=0.9$, they are 1.10 and -0.19 ). The results suggest that democracy is more effective in the most corrupt countries, while the effectiveness of economic freedom increases for the least corrupt countries. This result is consistent with Goel and Billger (2009). Third, the interaction effect of DEMO and EF is -0.12 (significant at the $1 \%$ level) for OLS and quantile $(\theta=0.5)$, implying a complementary effect of DEMO and EF at (conditional) mean and median. In other words, the result reflects that the joint effect of democracy and economic freedom combat corruption significantly. The quantile regression results confirm our hypothesis that the interaction effect of democracy and economic freedom is consistent throughout the conditional distribution of corruption. Interestingly, the quantile results also show that the interaction effect appears to be stronger among corrupt countries than clean ones $\left(\beta_{3}=-0.05\right.$ at $\theta=0.1$ and -0.20 at $\left.\theta=0.9\right)$.

Fourth, the socioeconomic control variables, except literacy rate, retain the expected sign although not being significant in every quantile (except for RGDP). That is higher values of income inequality and unemployment increase corruption, whereas a high income level decreases corruption.

The next step examines the partial effect of DEMO (EF) at different levels of EF (DEMO) throughout the conditional distribution of corruption across countries. We depict the relationship given by equations $3 \mathrm{a}$ and $3 \mathrm{~b}$ in Figure 1. Figure 1(A) indicates that EF significantly reduces corruption at any political environment as well as at any corruption level (as the partial

8 To interpret the signs of the coefficients, one should note that smaller values of the dependent variable denote less corruption. 


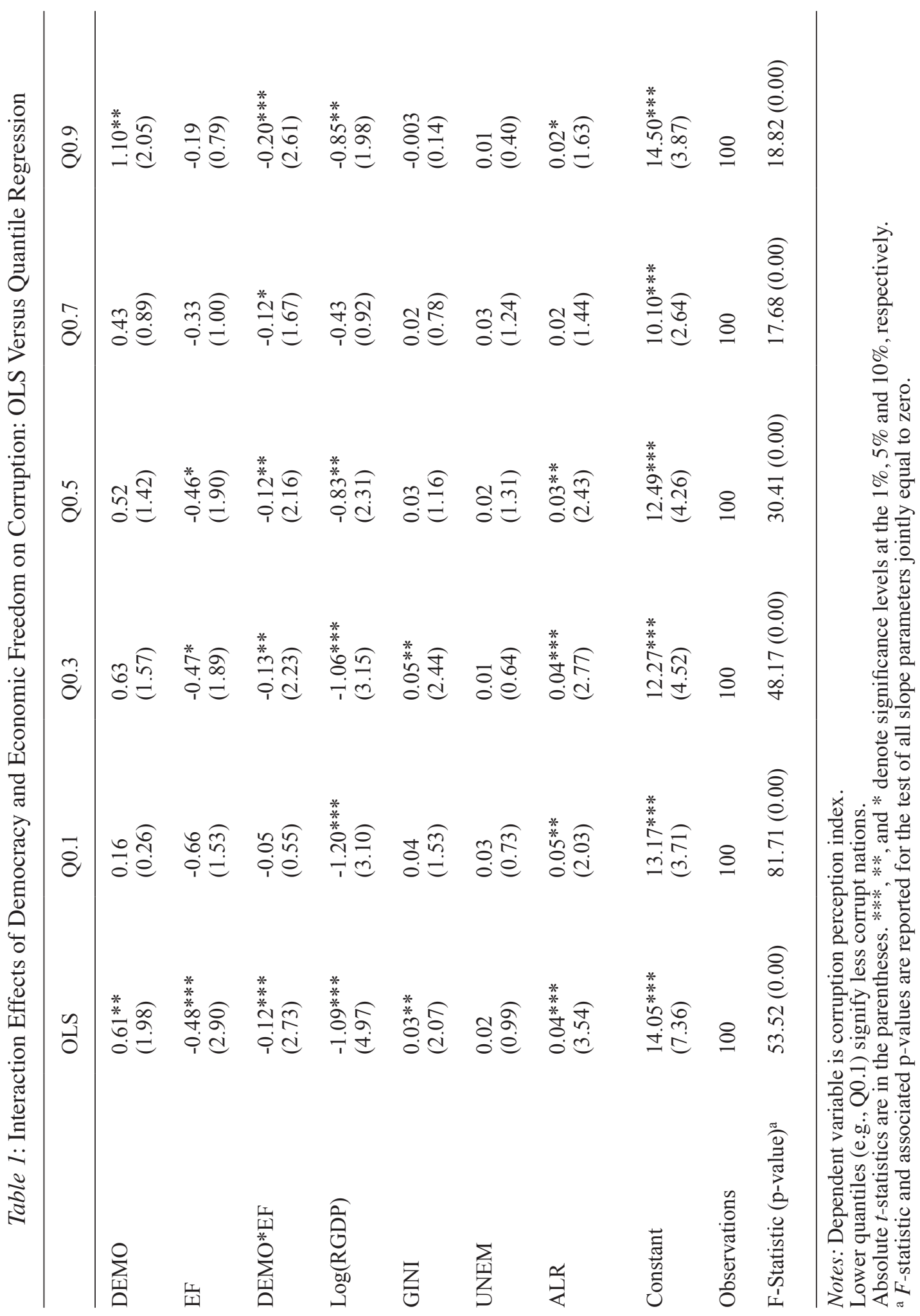


Figure 1: Partial Effects of Democracy and Economic Freedom

(A) Partial effect (Economic Freedom) at different levels of democracy and corruption

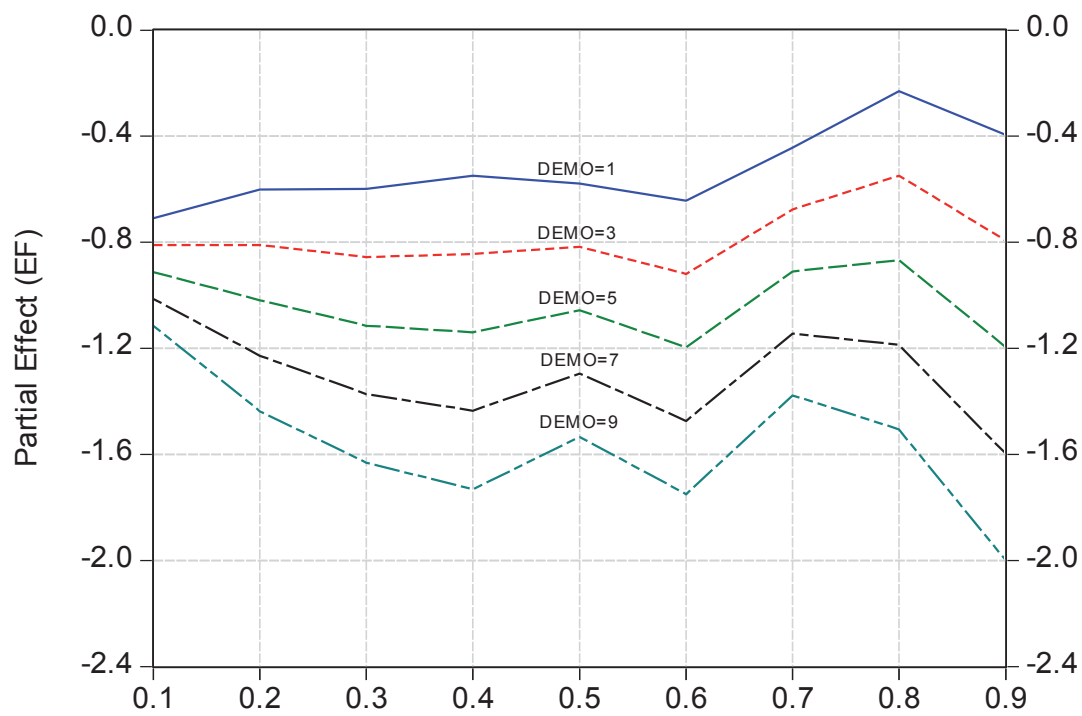

Quantile

(B) Partial effect (Democracy)

at different levels of economic freedom and corruption

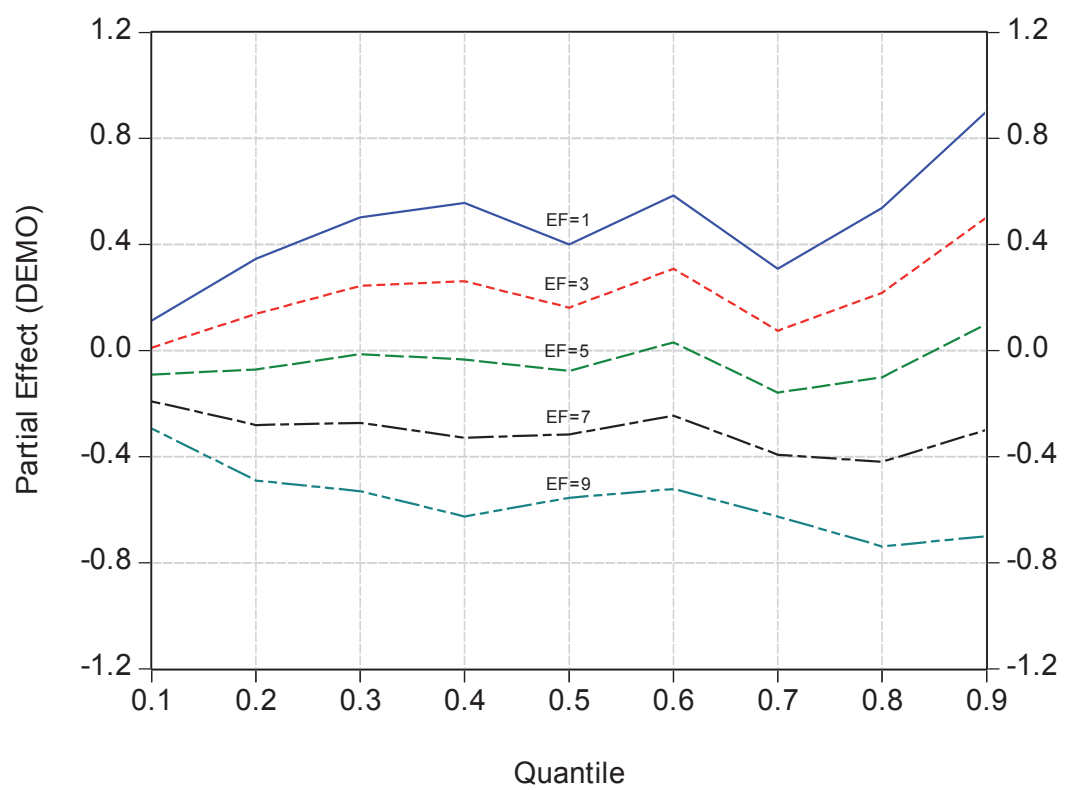


effects are all below zero). The partial effect of EF becomes stronger in a more democratic environment, given the same corruption quantile. Figure 1(A) also shows that the impact of $\mathrm{EF}$ on corruption is not homogenous at different corruption levels - for $\mathrm{DEMO}=1$ (less democratic), $\mathrm{EF}$ is more effective among clean countries but for $\mathrm{DEMO}=9$ (democratic), it is more effective among corrupt countries.

In contrast, Figure $1(B)$ shows that democracy at different levels of economic freedom produces mixed results. At the early stages of economic liberalization, greater democracy increases corruption opportunities and the situation worsens in the most corrupt countries. Democracy only helps in bringing down corruption (at all quantiles) if the level of economic freedom is above a certain threshold $(\mathrm{EF}=7)$. Above this threshold, the benefit of democracy in combating corruption becomes more noticeable for more corrupt countries. Overall, our result confirms the findings of Saha et al. (2009) and Billger and Goel (2009) that economic freedom does not help in reducing corruption in the most corrupt countries. But it also added that with the help of democratic freedom, economic liberalization can reduce corruption substantially in a most corrupt country. In other words, it is evident that a high level of economic freedom and democracy are more effective and efficient in reducing corruption in the most corrupt countries.

The result is consistent with some country specific examples. For instance, India has been a functioning and vibrant democracy for more than half a century but a higher democracy level has been unable to reduce corruption in India may be due to the existence of below average level of economic freedom. On the other hand, South Korea illustrates a good example of the democratization process and its deterring effect on corruption where there exists a far greater than average level of economic freedom. Moreover, a higher degree of economic freedom reduces corruption significantly in closed to authoritarian states (e.g., Hong Kong and Singapore) but the degree of influence is much less in most corrupt countries (China and Russia) where economic freedom is fairly low. The results manifest that the effect of economic freedom in curing corruption is much stronger in most corrupt countries at a higher level of democracy (above average). In other words, democracy can accelerate the anti-corruption reforms in particular for the most corrupt nations if there exists a high level of economic liberalization.

\section{CONCLUSIONS}

We have analysed how increased economic freedom and democracy deter corruption in both tails of the conditional distribution of corruption across countries. The in-depth partial effect quantile analysis reveals that the effects of democracy and economic freedom are not identical throughout the distribution. Economic freedom significantly reduces corruption at any political environment but the effectiveness increases at higher levels of freedom. We also find that the impact of economic freedom on corruption is not entirely homogenous at different levels of corruption. In contrast, democracy may not be effective in combating corruption at a low level of economic freedom (for countries at any degree of corruption), but democracy becomes effective in curing corruption for the most-corrupt countries when the level of economic freedom is high. The policy implication is that to reduce corruption, it is important for democratization to be done in an environment of high economic freedom. 


\section{ACKNOWLEGEMENTS}

We like to thank the referees for their valuable comments. The usual disclaimer applies.

\section{REFERENCES}

Ades, A. and R. Di Tella (1999). Rents, Competition, and Corruption, The American Economic Review. 89: 982-93.

Billger, S.M. and R.K. Goel (2009). Do Existing Corruption Levels Matter in Controlling Corruption? Cross-country Quantile Regression Estimates, Journal of Development Economics. 90: 299-305.

Bliss, C. and R. Di Tella (1997). Does Competition Kill Corruption?, Journal of Political Economy. 105: 1001-1023.

Goel, R.K. and M.A. Nelson (2007). Are Corrupt Acts Contagious?, Evidence from the United States, Journal of Policy Modelling. 29: 839-850.

Graeff, P. and G. Mehlkop (2003). The Impact of Economic Freedom on Corruption: Different Patterns for Rich and Poor Countries, European Journal of Political Economy. 19: 605-620.

Koenker, R. and G.J. Bassett (1978). Regression Quantiles, Econometrica. 46: 33-50.

Krueger, A.O. (1974). The Political Economy of the Rent-Seeking Society, American Economic Review. 64: 291-303.

Mohtadi, H. and T.L. Roe (2003). Democracy, Rent Seeking, Public Spending and Growth, Journal of Public Economic. 87: 445-466.

Montinola, G.R. and R.W. Jackman (2004). Sources of Corruption: A Cross-Country Study, British Journal of Political Science. 32: 147-170.

Okada, K. and S. Samreth (2012). The Effect of Foreign Aid on Corruption: A Quantile Regression Approach, Economics Letters. 115: 240-243.

Rock, M. (2007). Corruption and Democracy. UN/DESA Working paper, 55: 1-18.

Rose-Ackerman, S. (1978). Corruption: A Study in Political Economy. New York: Academic Press.

Saha, S., R. Gounder, and J.J. Su (2009). The Interaction Effect of Economic Freedom and Democracy on Corruption: A Panel Cross-Country Analysis, Economics Letters. 105: 173-76.

Treisman, D. (2000). The Causes of Corruption: A Cross-National Study, Journal of Public Economics. 76: 399-457.

Treisman, D. (2007). What Have We Learned About The Causes Of Corruption From Ten Years of Cross-National Empirical Research?, Annual Reviews Political Science. 10: 211-44. 